\title{
Distribution and Risk of Mycolactone-Producing Mycobacteria Transmission within Buruli Ulcer Endemic Communities in Côte d'Ivoire
}

\author{
Christelle Dassi ${ }^{1,2, \dagger}{ }^{\text {, Lydia Mosi }}{ }^{2,3,4, t, *}$, Charles A. Narh ${ }^{2,5, \dagger}$, Charles Quaye ${ }^{2,5}$, \\ Danièle O. Konan ${ }^{2}$, Joseph A. Djaman ${ }^{1}$ and Bassirou Bonfoh ${ }^{2}$ \\ 1 UFR Biosciences, Université Félix Houphouët Boigny, Abidjan, 01 BP V 34 Abidjan 01, Ivory Coast; \\ christelledassi@gmail.com (C.D.); djamanj@yahoo.fr (J.A.D.) \\ 2 Department of Environment and Health, Centre Suisse de Recherches Scientifiques en Côte d'Ivoire, \\ Adiopodoumé, 01 BP 1303, Abidjan 01, Ivory Coast; CakugbeyNarh@noguchi.ug.edu.gh (C.A.N.); \\ CQuaye@noguchi.ug.edu.gh (C.Q.); konandaniele@yahoo.fr (D.O.K.); bassirou.bonfoh@csrs.ci (B.B.) \\ 3 Biochemistry, Cell and Molecular Biology Department, University of Ghana, Legon, P. O. Box LG 54, Legon, \\ Accra, Ghana \\ 4 West African Centre for Cell Biology of Infectious Pathogens, University of Ghana, Legon, P. O. Box LG 54, \\ Legon, Accra, Ghana \\ 5 Parasitology Department, Noguchi Memorial Institute for Medical Research, Legon, P. O. Box LG 581, Legon, \\ Accra, Ghana \\ * Correspondence: lmosi@hotmail.com or lmosi@ug.edu.gh; Tel.:+233-54-0890352 \\ + These authors contributed equally to this work.
}

Academic Editor: John Frean

Received: 21 October 2016; Accepted: 22 February 2017; Published: 26 February 2017

\begin{abstract}
In Buruli ulcer (BU) endemic communities, most mycolactone-producing mycobacteria (MPM), including Mycobacterium ulcerans, the causative agent, are present in water bodies used by inhabitants; yet, their mode of transmission is still unclear. This study aimed to assess the distribution of MPM strains, both from human suspected cases and aquatic environments, for identifying possible transmission modes within two BU endemic districts, Daloa and Tiassalé (Taabo), in Côte d'Ivoire. Collected samples were processed using conventional polymerase chain reaction and screened for the presence of non-tuberculous mycobacteria (NTM) and MPMs using 16S rRNA, IS2404 and enoyl reductase (ER) primers. MPM-positive samples were further discriminated using variable number tandem repeat (VNTR) typing and sequencing. 16S rRNA and IS2404 sequences confirmed that $94 \%$ of the clinical samples contained MPMs. For environmental samples, 53\% were contaminated with NTMs, of which $17 \%$ contained MPMs particularly M. ulcerans, suggesting that water-related activities could predispose inhabitants to BU transmission. MPM discrimination by VNTR at four M. ulcerans Agy99 loci identified genotype C, previously reported in Côte d'Ivoire as the most dominant profile. Phylogenetic clustering on the basis of genetic diversity in the MIRU 1 locus showed two main M. ulcerans lineages in Côte d'Ivoire.
\end{abstract}

Keywords: mycolactone-producing mycobacteria; environment; human; transmission; Buruli ulcer; VNTR typing; phylogenetics

\section{Introduction}

Buruli ulcer (BU) is a necrotizing skin disease that has a huge socio-economic impact on affected individuals, their families and the community at large [1]. It is the third most common mycobacterial disease after tuberculosis and leprosy [2] and is endemic in more than thirty countries, particularly 
West Africa, including rural parts of Cameroon, Togo, Benin, Ghana and Côte d'Ivoire. About $48 \%$ of reported cases in Africa are in children below 15 years, and both genders are equally affected.

The causative microorganism, Mycobacterium ulcerans, is an environmental non-tuberculous mycobacterium (NTM), which produces mycolactone as its main virulence factor [1]. Recently, other mycolactone-producing mycobacteria (MPM) have been identified as novel species causing disease in fishes and frogs $[3,4]$. MPMs are therefore of huge importance to public health due to the devastating diseases they cause in humans and animals.

The transmission of these mycobacteria is still poorly understood, making it difficult to implement effective prevention and control strategies. Public health control efforts have focused on sensitization, active case detection and early treatment of infections in endemic communities [1,5-7]. Socio-economic activities around wetlands or slow-moving water bodies have been suggested as risk factors of infection [8-11]. Because of the difficulty in culturing M. ulcerans from aquatic environments [12], environmental studies have focused on the detection of M. ulcerans DNA [13-16]. These advances have enhanced our understanding of the epidemiology of some MPMs and improved the diagnosis of M. ulcerans.

PCR detection of mycobacterial DNA using 16S rRNA, the insertion sequences (IS2404 and IS2606) and genes encoding the enoyl and keto reductase (ER/KR) enzymes involved in the synthesis of $M$. ulcerans mycolactone have increased the rate of mycobacterium identification in clinical and environmental samples $[13,15,17]$. Additional discriminative tools including variable number tandem repeat (VNTR) and single-nucleotide polymorphism (SNP) typing have also been developed and successfully used to differentiate between MPMs [18-24].

Using these tools, we previously showed that individuals in BU endemic communities in Ghana may be infected from $M$. ulcerans-contaminated water bodies with which they frequently come into contact [16]. Thus, using similar approaches, we sought (1) to understand the distribution of MPMs in five BU endemic communities in Côte d'Ivoire, (2) to compare MPM strains, particularly M. ulcerans genotypes, between patients and environmental samples in water bodies they come into contact with, and (3) to determine the behavioral activities that might predispose inhabitants to M. ulcerans infection.

\section{Materials and Methods}

\subsection{Ethical Approval and Questionnaire Administration}

The study was conducted in accordance with the Declaration of Helsinki and received approval from the Ethics and Research National Committee (CNER) of the Health and AIDS control Ministry of Côte d'Ivoire (No. 3320/MSLS/CNER-P; Ministère de la Santé et de la Lutte contre le SIDA/Comité National d'Ethique et de la Recherche/Président). This was a cross-sectional study where the participants from the study communities were interviewed on their perception of BU disease. Samples were collected from patients who consented during an active case detection. The two activities were conducted at different time points with interviews preceding surveillance. The study was explained to participants, and informed written consent for each patient, or parent in the case of children, was obtained before enrolment into the study. Participants with confirmed BU infection, but not on treatment, were referred to a nearby approved BU clinic for treatment.

\subsection{Study Communities}

Study sites were selected based on BU endemicity data provided by the National Program for BU control (PNLUB). Selected communities were located in two major BU endemic areas in Côte d'Ivoire [25] with proximal and high-use aquatic ecosystems, including slow-moving water bodies. Daloa is a district (Haut-Sassandra) in the western centre approximately $406 \mathrm{~km}$ from the economic capital, Abidjan. This area is largely covered with forest and has the Sassandra River tributaries, which are used for irrigation, fishing and domestic activities. Gorodi and Zaibo were the two selected rural communities from Daloa. Three additional communities, Sokrogbo, Léléblé and Ahondo, within Taabo 
area (Tiassale district) were also included in this study. Taabo is in the southeastern part of the country approximately $160 \mathrm{~km}$ from Abidjan. Located within Taabo is a hydroelectric dam built over the Bandama River. There are several displaced villages along the river with associated socio-economic activities. Social and demographic characteristics of the population, as well as the frequency of contact with various aquatic environments were estimated by the use of structured questionnaires.

\subsection{Administration of Questionnaire}

As part of the bigger study, five hundred questionnaires were administered in the study communities from 12 February to 4 March 2012. The questionnaires mainly elicited information on the demographic characteristics of the community inhabitants, the main occupations of households, contact rates of the community members with various aquatic environments and animals, common diseases, BU knowledge and perception, and prevention and treatment. Communities were stratified into subsets based on population and reported cases of BU. Questionnaires were mainly administered to members of the household in the French language. Local languages were used only to verify unclear responses using the help of a trained local community aid.

\subsection{Collection of Human Samples}

Besides the administration of questionnaires, active case surveillance of BU suspected cases was undertaken with support from trained staff in the community health centers. Sample collection was performed during the dry season (17 to 26 September 2012) after questionnaire administration in the communities on both treated and untreated patients within the communities using protocols previously described [16]. Briefly, fine needle aspirations (FNA) or multiple swabs were collected at the health center by the medical staff in each community, depending on the type of lesion (nodule, edema or ulcer) (Figure 1). Each collected sample was placed in a sterile sample tube, which was labelled and stored on ice for transport to the laboratory.
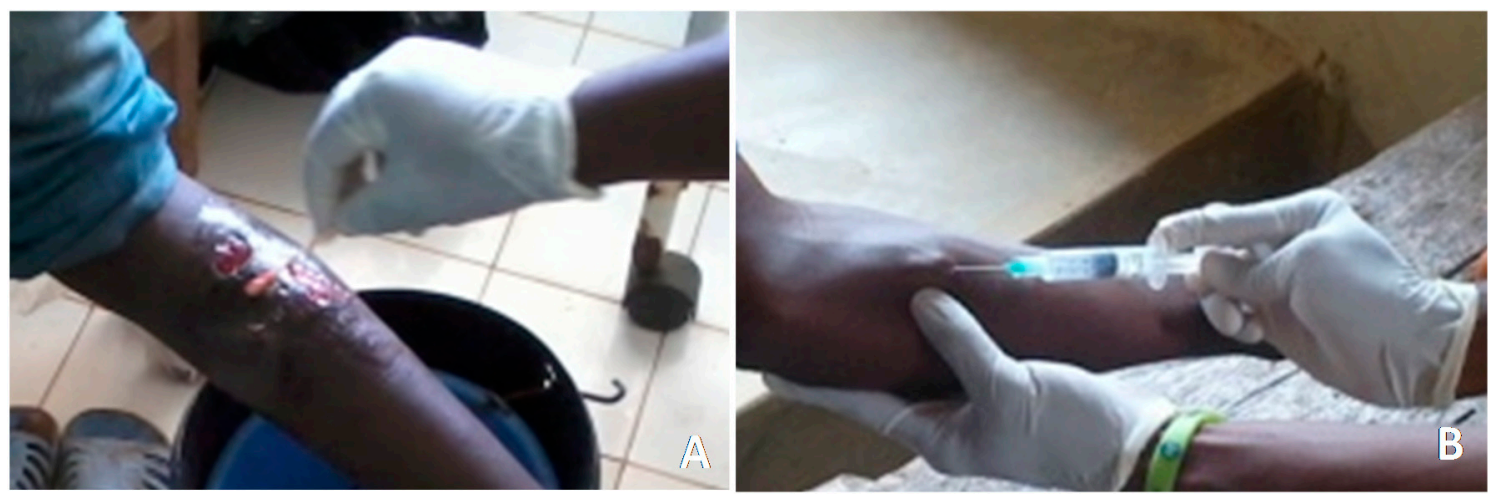

Figure 1. Sample collection from suspected cases. (A) Swab specimen collected from ulcer on a patient's leg; (B) fine needle aspiration collected from a nodule on a patient's arm.

\subsection{Environmental Sampling}

The environmental sample collection was performed during the dry season (17 to 26 September 2012). The water bodies sampled were selected based on frequency of use by community inhabitants for socio-economic activities as determined from questionnaire responses (Figure 2). Priority was given to water bodies that had undergone environment modifications based on activities such as farming, urbanization and construction of the hydroelectric dam.

Environmental sampling followed procedures described by Narh et al. [16]. Briefly, four different environmental matrices, soil, water filtrand, plant detritus and biofilms, were systematically collected using a quadrat-based sampling technique. Each sample was stored individually in 15- or 50-mL 
Falcon tubes with ethanol, kept on ice and transported to the laboratory for preservation at $4{ }^{\circ} \mathrm{C}$ until processing.
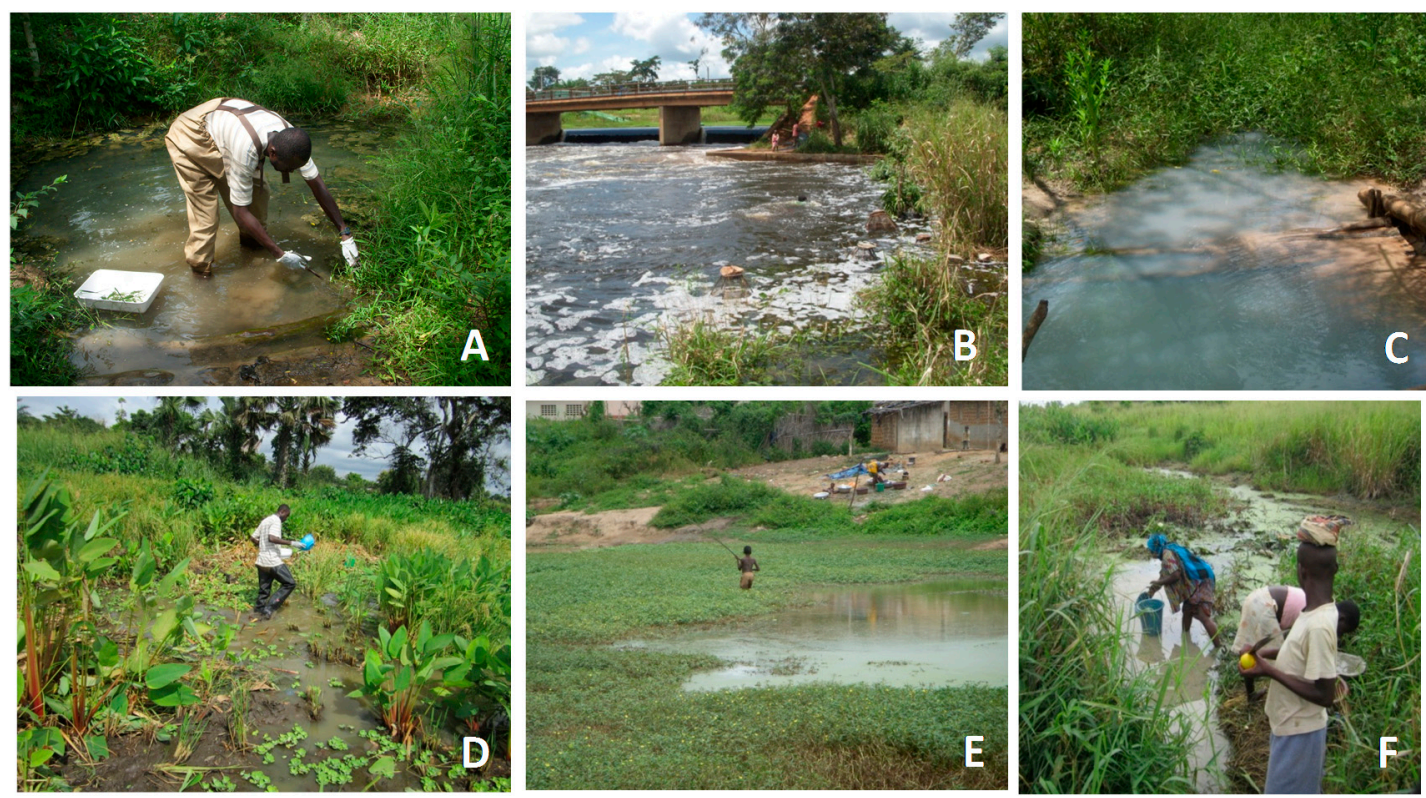

Figure 2. Some water bodies sampled within the study sites. (A) Plant sample collection in Tourou pond in Zaibo, Daloa district; (B) La Lobo River in Zaibo, Daloa district; (C) Nidrou1 pond in Gorodi, Daloa district; (D) sampling in Woudigné pond in Sokrogbo, Tiassalé district; (E) child fishing in Do pond in Léléblé, Tiassalé district; (F) inhabitants fetching water from Djapipo Barrage pond in Ahondo, Tiassalé district.

\subsection{DNA Extraction, Conventional PCR and Sequencing Analysis}

Total genomic DNA was extracted from lesion swabs and FNA samples using the QIAGEN DNeasy blood and tissue kit following the manufacturer's protocol. DNA extraction from environmental samples was performed following the methods described previously $[13,16]$. All PCR reactions were performed in a A206 gradient thermal cycler $\left(\right.$ LonGene ${ }^{\circledR}$ ) following described methods [16] using primers of the Mycobacterium 16S rRNA, the IS2404 insertion sequence, the enoyl reductase (ER) domain of the mycolactone-producing gene, as well as variable number tandem repeat (VNTR) loci MIRU 1, ST1, Locus 6 and Locus 19 (Tables S1 and S2). Negative and positive controls were included for each run.

DNA extracts from environmental samples were initially screened for Mycobacterium spp. using the Mycobacterium 16S rRNA primer. Positive samples were then screened for mycobacteria harboring the IS2404 insertion sequence using IS2404 PCR. Samples that were IS2404-positive were screened for the presence of the ER domain of the mycolactone-producing gene. Screening of human samples followed a similar order, but without the initial $16 \mathrm{~S}$ rRNA PCR.

In addition, 500- $\mu \mathrm{L}$ suspensions of each patient sample were decontaminated using the modified Petroff method [26]. The resulting pellet was streaked onto Lowenstein-Jensen slants and incubated for 36 weeks at $32{ }^{\circ} \mathrm{C}$ for isolation of mycobacteria.

All IS2404-positive samples were genotyped at four M. ulcerans VNTR loci; Locus 6, Locus 19, MIRU 1 and ST1. Length polymorphism was estimated from the size of the PCR product following separation on agarose gel and based on included positive controls as described by previous studies [13,16,19,27-30]. We used M. ulcerans 1615 strain, M. liflandii and M. marinum DL as the positive controls for the VNTR typing. Representative amplicons with good PCR products for each primer set from both human and environmental samples were sequenced using the forward and reverse primers in Sanger sequencing (Macrogen Inc., Netherlands). The sequences were queried 
against the NCBI nucleotide database using BLAST [31]. The E-value to consider homology and used for species ID confirmation was chosen to be below $10^{-4}$ or 0.0001 . Search queries returning first hits with $>70 \%$ nucleotide similarity were used to characterize isolates.

\subsection{Statistical and Phylogenetic Analysis}

Molecular data were recorded and stored in Microsoft Excel. The questionnaire data were analyzed using EpiData V 3.1. Alignments of queried sequences were performed using MAFFT [32], and the phylogenetic tree was drawn using FastTree [33] based on the maximum likelihood. FastTree incorporates the Jukes-Cantor model of nucleotide substitution; the distance is $-0.75 \times \log (1-4 / 3 \times \mathrm{d})$, where $\mathrm{d}$ is the proportion of positions that differ. When comparing two sequences, positions with gaps are ignored; when comparing two profiles, positions are weighted by their proportions of non-gaps. To account for the varying rates of evolution across sites, FastTree uses a single rate for each site (the 'CAT' (categories) approximation). To estimate the reliability of each split in the tree, FastTree computes local support values, based on 1000 resampling, with the Shimodaira-Hasegawa test. Statistical analysis was performed in Excel and Stata V12, and $p<0.05$ for sample positivity comparison was considered statistically significant.

\section{Results}

\subsection{Demographic Profile and Socio-Economic Activities Related to Water Bodies}

Of the 500 questionnaires, $58 \%$ were administered to males and $42 \%$ to females. Ages of respondents ranged from 18 to 98 years old with a mean of 42.5 years. However, the majority, $31 \%(95 \%$ CI, $27 \%$ to $35 \%)$ were within the 26 to 35 years age group. The proportions of water-related socio-economic activities identified by respondents within communities are shown in Figure 3.

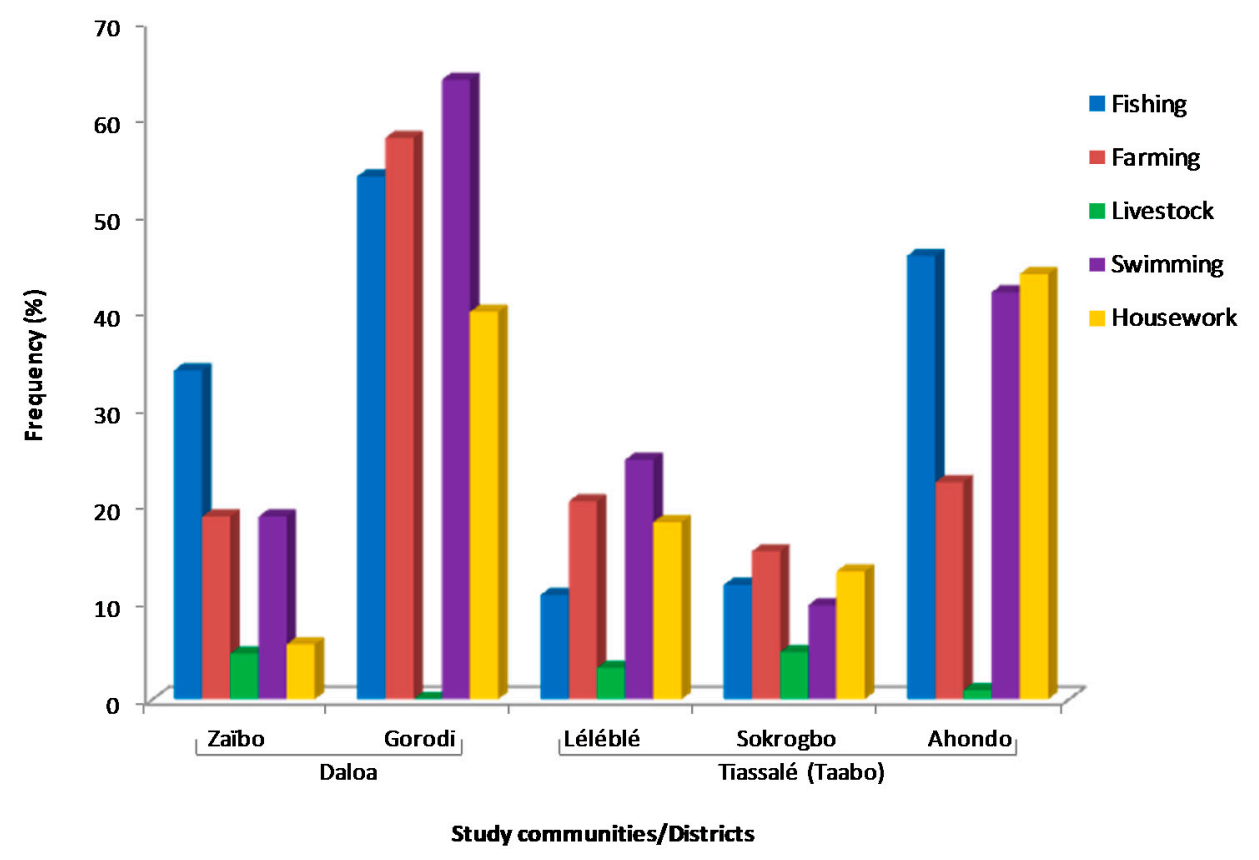

Figure 3. Proportion of respondents involved in water-related socio-economic activities. Farming included plant crop watering and irrigated crops; livestock represented livestock watering; swimming was considered as a children's leisure activity; housework activities included water fetching for laundry, washing-up, crude food washing, drinking and bathing.

The major socio-economic activities related to contact with environmental water bodies were fishing, farming (plant crop watering and irrigated crops), swimming and housework-related activities. 
Fishing was the main economic activity in the Ahondo and Zaibo communities with $46 \%$ and $34 \%$ of respondents involved, respectively. In contrast, farming was the main economic activity in the Gorodi, Léléblé and Sokrogbo communities, with 58\%, 20\% and 15\% of respondents involved, respectively. Swimming was also identified as the main water-related social activity for children, mostly in Gorodi $(84 \%)$ and Ahondo (42\%). Domestic activities including laundry, washing of dishes and raw farm produce and fetching water, were also undertaken by both children and adults, particularly in Ahondo $(44 \%)$ and Gorodi (40\%).

\subsection{Confirmation of Clinical Cases and Incidence of BU within Communities}

A total of 35 samples was collected from 30 BU suspected clinical cases (Table 1). Of these, $80 \%$ were collected from Tiassalé district (Taabo), whilst the remaining 20\% were collected from Daloa district. Clinical data relating to BU suspected cases are shown in Table 1. The proportions of BU suspected cases were equal (50\%) for males and females. The ages of patients ranged from 6 to 70 years with a mean age of 29 years. Based on the IS2404 amplification results, 30\% (95\% CI; $14 \%$ to $46 \%$ ) of the BU confirmed clinical cases were patients $<18$ years, while $70 \%$ ( $95 \%$ CI; $54 \%$ to $86 \%$ ) were patients $\geq 18$ years; this difference was statistically significant $(p=0.002)$. The majority of samples $(94.3 \%)$ were taken from ulcers. The IS2404 insertion sequence was detected in 33 samples out of 35 representing a BU confirmation positivity of $94 \%$ in the suspected clinical cases; that is, 28 out of 30 patients (three samples were patient duplicates). Thus, $100 \%$ of samples from Ahondo, Léléblé, Gorodi and Sokrogbo were IS2404-positive as compared to 33\% from Zaibo. Although ER PCR was attempted for all samples, only seven samples (21\%) gave visible bands on agarose gel (Table 1, Figures S1 and S2).

Incubation on Löwestein-Jensen (LJ) culture slants for each patient for nine months showed that the majority of the tubes $(n=27)$ had no growth at the end of this period. We observed growth in a few tubes $(n=3)$, but upon further characterization using microscopy and PCR amplification using the same primers as above, none of the cultures were confirmed as M. ulcerans.

\subsection{Genotyping and Discrimination of Human Strains}

VNTR-PCR genotyping at Locus 6, Locus 19, MIRU 1 and ST1 was attempted twice for all IS2404-positive samples, but PCR was successful for only seven (21\%), based on at least two loci (Table 2). VNTR profiles were determined according to repeat number variation for PCR product sizes. Positive controls with known repeat numbers were run alongside isolates (Figure S3). Length polymorphisms were further confirmed with sequencing. However, for some samples, it was not possible to determine repeat numbers for VNTR loci, as a few sequence reads were not of good quality. Only reads with an average quality of 20 (Phred score) were further processed for repeat confirmation and phylogenetic analysis. Repeat sequences reported by Narh et al. [16] were used as references.

Figure 4 shows the MIRU 1 loci repeat variation for three human samples (SL3, SS2 and SA9), one Ghanaian M. ulcerans strain (GenBank ID, KM459596) and M. ulcerans Agy99. The human samples and M. ulcerans Agy99 each had a repeat of three. KM459596 (Ghana (Gh)) had one repeat as previously reported [16]. However, we detected a few single-nucleotide polymorphisms (SNPs) in the repeat sequences of some samples, including SA9.

VNTR profiles were arranged in order of MIRU 1, Locus 6, ST1 and Locus 19. A total of four allelic profiles, including $(3,1,2,2),\left(1,1,{ }_{-}\right),\left(9,1,{ }_{-}\right)$and $\left(, 1,{ }_{-}, 4\right)$, were observed (Table 2$)$. The two allelic profiles $(3, \ldots, 2,2)$ and $(3,1, \ldots)$ that were also observed could be other profiles or considered as incomplete profiles of $(3,1,2,2)$ (C profile). Unsuccessful amplification at a marker is indicated by a dashed line. The profile $\left(1,1,{ }_{-}\right)$was similar to allelic repeats for MIRU 1 and Locus 6 in previously reported Ghanaian M. ulcerans genotypes, W, X and A [13,16]. For this study, Locus 6 and ST1 were monomorphic, with one and two repeats, respectively. In contrast, MIRU 1 gave repeat variations of 1,3 and 9, and Locus 19 had two and four.

However, the presumptive profile $(3,1,2,2)$, associated with strains from Léléblé, Sokrogbo and Ahondo localities, was similar to profile $C$ already reported in Ghana and Côte d'Ivoire. This 
length polymorphism was also present in the reference strain M. ulcerans Agy99 [13,34] (Figure 4). In Daloa district (Zaibo and Gorodi communities), genotype profiles could not be determined due to unsuccessful amplification of the VNTR loci.

Table 1. Clinical data on Buruli ulcer (BU) suspected cases within communities. ER, enoyl reductase.

\begin{tabular}{|c|c|c|c|c|c|c|c|c|}
\hline \multicolumn{7}{|c|}{ Clinical History } & \multicolumn{2}{|c|}{ PCR Test } \\
\hline District & Community & Sample Code & Sex & Age (years) & Lesion & Specimen & IS2404 & ER \\
\hline \multirow{7}{*}{ Daloa } & \multirow{3}{*}{ Zaïbo } & SZ1 & M & 27 & ulcer & swab & Pos & Neg \\
\hline & & SZ2 & $\mathrm{F}$ & 65 & ulcer & swab & Neg & Neg \\
\hline & & SZ3 & F & 27 & ulcer & swab & $\mathrm{Neg}$ & $\mathrm{Neg}$ \\
\hline & \multirow{4}{*}{ Gorodi } & FG1 & M & 21 & nodule & FNA & Pos & Neg \\
\hline & & SG2 & $\mathrm{F}$ & 29 & ulcer & swab & Pos & Neg \\
\hline & & SG3 & F & 70 & ulcer & swab & Pos & $\mathrm{Neg}$ \\
\hline & & SG4 & $\mathrm{F}$ & 48 & ulcer & swab & Pos & Neg \\
\hline \multirow{28}{*}{$\begin{array}{l}\text { Tiassalé } \\
\text { (Taabo) }\end{array}$} & \multirow{5}{*}{ Léléblé } & SL1 & $\mathrm{M}$ & 7 & ulcer & swab & Pos & $\mathrm{Neg}$ \\
\hline & & SL2 & M & 7 & ulcer & swab & Pos & $\mathrm{Neg}$ \\
\hline & & SL3 & $\mathrm{F}$ & 43 & ulcer & swab & Pos & Pos \\
\hline & & SL4a & M & 10 & ulcer & swab & Pos & $\mathrm{Neg}$ \\
\hline & & SL4b & M & 10 & ulcer & swab & Pos & Neg \\
\hline & \multirow{10}{*}{ Sokrogbo } & SS1 & $\mathrm{M}$ & 60 & ulcer & swab & Pos & $\mathrm{Neg}$ \\
\hline & & SS2 & $\mathrm{F}$ & 10 & ulcer & swab & Pos & Pos \\
\hline & & SS3 & F & 56 & ulcer & swab & Pos & $\mathrm{Neg}$ \\
\hline & & SS4 & F & 19 & ulcer & swab & Pos & Neg \\
\hline & & SS5 & $\mathrm{F}$ & 30 & ulcer & swab & Pos & Neg \\
\hline & & SS6a & M & 17 & ulcer & swab & Pos & $\mathrm{Neg}$ \\
\hline & & SS6b & M & 17 & ulcer & swab & Pos & Neg \\
\hline & & SS7 & $\mathrm{F}$ & 20 & ulcer & swab & Pos & Neg \\
\hline & & SS8 & $\mathrm{F}$ & 30 & ulcer & swab & Pos & $\mathrm{Neg}$ \\
\hline & & SS9 & M & 36 & ulcer & swab & Pos & Neg \\
\hline & \multirow{13}{*}{ Ahondo } & SA1 & $M$ & 12 & ulcer & swab & Pos & Pos \\
\hline & & SA2 & M & 50 & ulcer & swab & Pos & Neg \\
\hline & & SA3a & M & 25 & ulcer & swab & Pos & Neg \\
\hline & & SA3b & M & 25 & ulcer & swab & Pos & $\mathrm{Neg}$ \\
\hline & & FA4 & $\mathrm{M}$ & 49 & nodule & FNA & Pos & $\mathrm{Neg}$ \\
\hline & & SA6 & $\mathrm{F}$ & 13 & ulcer & swab & Pos & Pos \\
\hline & & SA7 & $\mathrm{F}$ & 18 & ulcer & swab & Pos & $\mathrm{Neg}$ \\
\hline & & SA8 & M & 44 & ulcer & swab & Pos & Neg \\
\hline & & SA9 & $\mathrm{F}$ & 6 & ulcer & swab & Pos & Pos \\
\hline & & SA10 & M & 12 & ulcer & swab & Pos & Pos \\
\hline & & SA11 & M & 10 & ulcer & swab & Pos & Pos \\
\hline & & SA12a & $\mathrm{M}$ & 44 & ulcer & swab & Pos & Neg \\
\hline & & SA12b & M & 44 & ulcer & swab & Pos & $\mathrm{Neg}$ \\
\hline
\end{tabular}

M: male; F: female; FNA: fine needle aspiration; SZ: swab lesion Zaibo; FG: FNA Gorodi; SG: swab lesion Gorodi; SL: swab lesion Léléblé; SS: swab lesion Sokrogbo; SA: swab lesion Ahondo; FA: FNA Ahondo; Pos: positive; Neg: negative. IS2404 positivity: Zaïbo (33\%), Gorodi (100\%), Léléblé (100\%), Sokrogbo (100\%) and Ahondo (100\%).

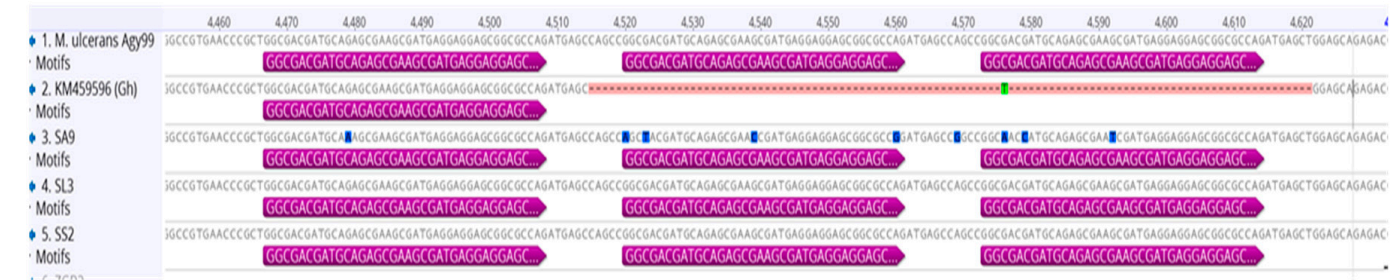

Figure 4. Sequence confirmation of MIRU 1 repeats in human samples. MIRU 1 reference sequences used were two orthologs from M. ulcerans Agy99 and the Ghanaian strain with Accession Numbers CP000325.1 and KM459596, respectively. The three human samples shown had a repeat variation of three for MIRU 1 as the reference strain M. ulcerans Agy99, while the Ghanaian strain had a repeat of one. 
Table 2. VNTR typing and allelic profile from BU confirmed clinical samples and African mycolactone-producing mycobacteria (MPM) genotypes from published data.

\begin{tabular}{|c|c|c|c|c|c|c|c|}
\hline \multicolumn{8}{|c|}{ BU Confirmed Clinical Cases } \\
\hline \multirow{2}{*}{ Community } & \multirow{2}{*}{ Sample Code } & \multicolumn{4}{|c|}{ Allelic Profiles } & \multirow{2}{*}{ Genotype } & \multirow{2}{*}{ Reference } \\
\hline & & MIRU1 & Locus 6 & ST1 & Locus 19 & & \\
\hline \multirow{2}{*}{ Léléblé } & SL2 & 1 & 1 & $\mathrm{~N} / \mathrm{D}$ & $\mathrm{N} / \mathrm{D}$ & \multirow{2}{*}{$\begin{array}{l}\text { undetermined } \\
\text { C- }\end{array}$} & \multirow{2}{*}{$\begin{array}{c}\text { current study } \\
{[13,34]}\end{array}$} \\
\hline & SL3 & 3 & $\mathrm{~N} / \mathrm{D}$ & 2 & 2 & & \\
\hline \multirow{2}{*}{ Sokrogbo } & SS1 & 9 & 1 & $\mathrm{~N} / \mathrm{D}$ & $\mathrm{N} / \mathrm{D}$ & \multirow{2}{*}{$\begin{array}{l}\text { undetermined } \\
\text { C- }\end{array}$} & \multirow{2}{*}{$\begin{array}{c}\text { current study } \\
{[13,34]}\end{array}$} \\
\hline & SS2 & 3 & $\mathrm{~N} / \mathrm{D}$ & 2 & 2 & & \\
\hline \multirow{3}{*}{ Ahondo } & SA2 & $\mathrm{N} / \mathrm{D}$ & 1 & $\mathrm{~N} / \mathrm{D}$ & 4 & \multirow{3}{*}{$\begin{array}{c}\text { undetermined } \\
\text { C- } \\
\text { C }\end{array}$} & \multirow{3}{*}{$\begin{array}{c}\text { current study } \\
{[13,34]} \\
{[13,34]}\end{array}$} \\
\hline & SA9 & 3 & 1 & $\mathrm{~N} / \mathrm{D}$ & $\mathrm{N} / \mathrm{D}$ & & \\
\hline & SA10 & 3 & 1 & 2 & 2 & & \\
\hline \multicolumn{8}{|c|}{ Published African MPM Genotypes } \\
\hline \multicolumn{6}{|c|}{ Allelic Profiles } & \multirow{2}{*}{ Genotype } & \multirow{2}{*}{ Reference } \\
\hline MP & Strain & MIRU1 & Locus 6 & ST1 & Locus 19 & & \\
\hline \multirow{4}{*}{\multicolumn{2}{|c|}{ M. ulcerans }} & 1 & 1 & 1 & 2 & A & \multirow{6}{*}{ [35] } \\
\hline & & 3 & 1 & 1 & 2 & B & \\
\hline & & 3 & 1 & 2 & 2 & $\mathrm{C}$ & \\
\hline & & 1 & 1 & 2 & 2 & $\mathrm{D}$ & \\
\hline \multicolumn{2}{|c|}{$\begin{array}{l}\text { Mycolactone-producing } \\
\text { M. marinum and M. pseudoshottsii }\end{array}$} & 1 & 4 & 2 & 2 & MPM & \\
\hline \multicolumn{2}{|c|}{$\begin{array}{c}\text { Mycolactone-producing } \\
\text { M. liflandii }\end{array}$} & 1 & 2 & 2 & 1 & MPML & \\
\hline
\end{tabular}

N/D: non-amplified locus; SL: swab lesion Léléblé; SS: swab lesion Sokrogbo; SA: swab lesion Ahondo; C-: incomplete profile of genotype C.

\subsection{Distribution of MPMs in Environmental Samples from Water Bodies}

A total of 195 environmental samples was collected from 15 water bodies, 3 rivers and 12 ponds. These water bodies were identified as frequently used by inhabitants living within the study communities. At each water body, biofilms were collected in quintuplicates, water filtrands in duplicates, and both plant detritus and soils in triplicates. Each sample set collected was screened for mycobacterial 16S rRNA positivity. Those positive were then screened for the insertion sequence, IS2404 (Table 3, Table 4 and Figure S4). We collected four matrices; 75 aquatic plant biofilms, 30 water filtrands, 45 plant detritus and 45 soil samples. Overall, the positivity rate for $16 \mathrm{~S}$ rRNA was $53 \%$ (95\% CI; $46 \%$ to $60 \%$ ) while IS2404 positivity (IS2404 positives / $16 \mathrm{~S}$ rRNA positives) was $17 \%$ (95\% CI; $9.3 \%$ to $24 \%)$. NTM positivity was highest in water filtrands (67\%) and lowest in soils (44\%) based on $16 \mathrm{~S}$ rRNA detection. Interestingly, water filtrands and soil samples gave the highest $(25 \%)$ and lowest $(5 \%)$ positivity for MPMs, respectively based on IS2404 DNA detection. All samples collected from Tourou pond in Zaibo were positive for NTMs, but none from Djapipo barrage pond in Ahondo were positive. In a separate subgroup analysis, we observed that the mean NTM positivity for Daloa district, $71 \%$ (95\% CI; $61 \%$ to $81 \%)$, was significantly $(p<0.001)$ higher than Tiassale district, $41 \%$ (95\% CI; $32 \%$ to $50 \%$ ). However, although the mean MPM positivity was also higher in Daloa, $18 \%$ (95\% CI; $8 \%$ to $28.4 \%$ ) than Tiassale district, $17 \%$ (95\% CI; $6 \%$ to $27 \%)$, the difference was not statistically significant $(p=0.820)$. VNTR-PCR for most IS2404-positive samples gave non-specific bands for all loci except for MIRU 1, which gave variable repeat sizes in $12 \%$ of the samples (Figure S5). Representatives of these were confirmed with sequencing. 
Table 3. 16S rRNA and IS2404 positivity in water bodies.

\begin{tabular}{|c|c|c|c|c|}
\hline & Communities & Water Bodies & $16 S$ rRNA $N^{\circ}(\%)$ & IS2404 $\mathrm{N}^{\circ}(\%)$ \\
\hline \multirow{7}{*}{ Daloa } & \multirow{3}{*}{ Zaïbo } & Gbouwa pond & $9 / 13(69.23 \%)$ & $4 / 9(44.44 \%)$ \\
\hline & & Tourou pond & $13 / 13(100 \%)$ & $1 / 13(7.69 \%)$ \\
\hline & & La Lobo River & $11 / 13(84.62 \%)$ & $2 / 11(18.18 \%)$ \\
\hline & \multirow{3}{*}{ Gorodi } & Godo River & $7 / 13(53.85 \%)$ & $1 / 7(14.26 \%)$ \\
\hline & & Nidrou 1 pond & $5 / 13(38.46 \%)$ & $0 / 5(0 \%)$ \\
\hline & & Nidrou 2 pond & $10 / 13(76.92 \%)$ & $2 / 10(20 \%)$ \\
\hline & \multicolumn{2}{|l|}{ Sub-total } & $55 / 78(71.0 \%)$ & $10 / 55(18.2 \%)$ \\
\hline \multirow{11}{*}{ Tiassalé } & \multirow{4}{*}{ Léléblé } & N'ziba pond & $11 / 13(84.62 \%)$ & $1 / 11(9.09 \%)$ \\
\hline & & Do pond & $7 / 13(53.85 \%)$ & $0 / 7(0 \%)$ \\
\hline & & Barrage pond & $5 / 13(38.46 \%)$ & $1 / 5(20 \%)$ \\
\hline & & Lahôbloua pond & $10 / 13(76.92 \%)$ & $1 / 10(10 \%)$ \\
\hline & \multirow{3}{*}{ Sokrogbo } & Woudigné pond & $4 / 13(30.77 \%)$ & $2 / 4(50 \%)$ \\
\hline & & Barrage 1 pond & $4 / 13(30.77 \%)$ & $0 / 4(0 \%)$ \\
\hline & & Barrage 2 pond & $2 / 13(15.38 \%)$ & $0 / 2(0 \%)$ \\
\hline & \multirow{2}{*}{ Ahondo } & Djapipo Barrage pond & $0 / 13(0 \%)$ & $0 / 0(0 \%)$ \\
\hline & & Bandama River & $5 / 13(38.46 \%)$ & $2 / 5(40 \%)$ \\
\hline & sub-total & & $48 / 117(41 \%)$ & $7 / 48(14.5 \%)$ \\
\hline & Overall Prevalence & & $103 / 195(52.82 \%)$ & $17 / 103(16.50 \%)$ \\
\hline
\end{tabular}

Table 4. 16S rRNA and IS2404 positivity in environmental matrices.

\begin{tabular}{|c|c|c|c|}
\hline & Sample Matrices & 16S rRNA $\mathrm{N}^{\circ}(\%)$ & IS2404 $\mathrm{N}^{\circ}(\%)$ \\
\hline \multirow{5}{*}{ Sample Type } & Plant biofilm & $38 / 75(50.67 \%)$ & $7 / 38(18.42 \%)$ \\
\hline & Water filtrand & $20 / 30(66.67 \%)$ & $5 / 20(25 \%)$ \\
\hline & Plant detritus & $25 / 45(55.56 \%)$ & $4 / 25(16 \%)$ \\
\hline & Soil & $20 / 45(44.44 \%)$ & $1 / 20(5 \%)$ \\
\hline & Total & $103 / 195(52.82 \%)$ & $17 / 103(16.50 \%)$ \\
\hline
\end{tabular}

\subsection{Comparison of Human and Environmental MPM Strains}

Based on read length and quality, IS2404 sequences were used to identify and differentiate the MPM species in the human and environmental samples, as supplementary characterization (Table 5). The IS2404 sequences identified all environmental samples, except SS1, SA2, SA10 and GGB4 (Gorodi Godo biofilm 4), as M. liflandii. One human sample, SA2, was identified as M. ulcerans. Interestingly, two human samples, SS1 and SA10, were identified as M. pseudoshottsii using the IS2404 sequences.

\subsection{Genotypes from Côte d'Ivoire Share Homology with Ghanaian Genotypes, but Maintain Unique Sub-Clusters}

We sought to identify similarities between the genotypes identified in this study and those of previously-reported profiles in the sub-region. Figure 5 shows the phylogenetic relationship, based on the MIRU 1 locus, between genotypes from the current study (human and environmental) and those from Ghana, including M. ulcerans Agy99. KM459596_Gh, FW2_Gh, BAB4_Gh, FY1_Gh and SKB5_Gh are M. ulcerans strains reported by Narh et al. [16]. 
Table 5. Identification of MPM strains based on IS2404 sequence similarity.

\begin{tabular}{|c|c|c|c|}
\hline \multicolumn{4}{|c|}{ Clinical Isolates } \\
\hline District & Community & Type of Sample (ID) & IS2404 Identity \\
\hline \multirow{9}{*}{ Tiassalé (Taabo) } & Léléblé & Lesion swab (SL3) & $98 \%$ for M. liflandii $128 \mathrm{FXT}$ \\
\hline & \multirow{5}{*}{ Sokrogbo } & Lesion swab (SS1) & $97 \%$ for M. pseudoshottsii L15 \\
\hline & & Lesion swab (SS2) & $97 \%$ for M. liflandii 128 FXT \\
\hline & & Lesion swab (SS6a) & $\mathrm{N} / \mathrm{D}$ \\
\hline & & Lesion swab (SA2) & $96 \%$ for M. ulcerans Agy 99 \\
\hline & & Lesion swab (SA3b) & $\mathrm{N} / \mathrm{D}$ \\
\hline & \multirow[t]{3}{*}{ Ahondo } & Lesion swab (SA9) & $\mathrm{N} / \mathrm{D}$ \\
\hline & & Lesion swab (SA10) & $95 \%$ for M. pseudoshottsii L15 \\
\hline & & Lesion swab (SA12a) & $\mathrm{N} / \mathrm{D}$ \\
\hline \multicolumn{4}{|c|}{ Environmental Isolates } \\
\hline \multirow{4}{*}{ Daloa } & Zaïbo & Gbouwa pond/water filtrand (ZGF1) & $\mathrm{N} / \mathrm{D}$ \\
\hline & & Tourou pond/water filtrand (ZTF1) & $89 \%$ for $M$. liflandii 128 FXT \\
\hline & Gorodi & Godo River/plant biofilm (GGB4) & $96 \%$ for Mycobacterium sp. YM-1 \\
\hline & & Nidrou2 pond/plant biofilm (GN2B5) & $97 \%$ for $M$. liflandii 128 FXT \\
\hline \multirow{4}{*}{ Tiassalé (Taabo) } & Léléblé & N'Ziba pond/plant biofilm (LNB1) & $99 \%$ for M. liflandii $128 \mathrm{FXT}$ \\
\hline & \multirow{3}{*}{ Sokrogbo } & Lahôbloua pond/plant biofilm (LLB5) & $\mathrm{N} / \mathrm{D}$ \\
\hline & & Woudigné pond/plant detritus (SWD1) & $\mathrm{N} / \mathrm{D}$ \\
\hline & & Woudigné pond/plant detritus (SWD3) & $99 \%$ for M. liflandii $128 \mathrm{FXT}$ \\
\hline
\end{tabular}

N/D, Not identified. Percentage (\%) identity of the IS2404 sequence to reference orthologs.

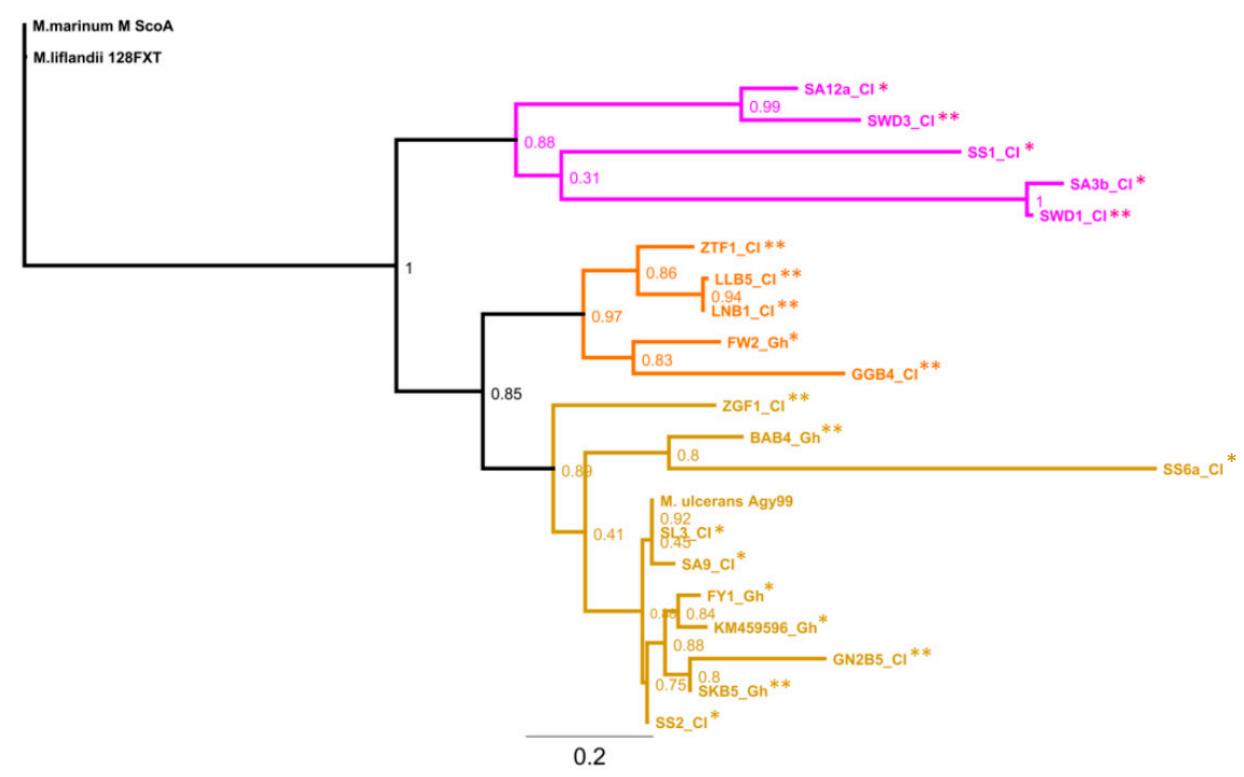

Figure 5. Phylogenetic tree of MPM isolates from human $\left(^{*}\right)$ and environmental $\left({ }^{* *}\right)$ samples based on the MIRU 1 locus. Samples from the current study (Côte d'Ivoire) and Ghana are indicated with the suffix CI and Gh, respectively. Cluster 1 (CI 1) in purple and CI 2, in orange, are comprised of isolates mainly from Côte d'Ivoire. Cluster CI 3 shown in brown includes samples from Ghana and Côte d'Ivoire. The tree was rooted on M. marinum. The bootstrap (1000 resampling) values are shown beside the branches.

The tree was rooted using M. marinum as the common ancestor. Three main clusters (clades) were observed; clusters of samples from current study in Côte d'Ivoire (CI), CI 1 (purple), CI 2 (orange) and CI 3 (brown) with reliability (out of 1000 resampling) values of $88 \%, 97 \%$ and $89 \%$, respectively. Five isolates, both human and environmental, from Côte d'Ivoire (purple) formed CI 1. The second cluster (CI 2) was comprised of four environmental isolates from Côte d'Ivoire and one human M. ulcerans 
isolate from Ghana. The third cluster (CI 3) was comprised of four environmental and seven human isolates from both Ghana and Côte d'Ivoire. This clade was comprised of smaller sub-clades.

\section{Discussion}

Mycobacterium ulcerans infection is prevalent in most rural communities in Côte d'Ivoire, but there is little information on the epidemiology of MPMs in the environment or whether they may be responsible for some of the human disease cases. It has become increasingly apparent that close contacts with contaminated aquatic ecosystems are major risk factors for M. ulcerans infection. Our previous findings in Ghana suggested that source tracking of contaminated water bodies is pertinent in uncovering the elusive mode of transmission of the disease [16]. Extending in this, we explored the distribution of MPMs in two BU endemic districts in Côte d'Ivoire and confirmed that common mycobacterial strains could be detected in humans and their proximal aquatic environments.

PCR detection of the IS2404 and ER genes, supported with sequencing, was the confirmatory test for M. ulcerans infection in suspected cases. We were however unsuccessful in our attempts to isolate M. ulcerans from the LJ culture slants. Based on the sequence data, a lower temperature incubation other than $32{ }^{\circ} \mathrm{C}$ may have been helpful in the isolation and growth of the MPMs. This assertion was previously alluded to in a study that showed the diversity of PCR positivity in culture-positive and -negative patient samples in Ghana [35]. We were therefore limited to the reliance on PCR and sequencing for our data interpretation. This is not an unusual occurrence in M. ulcerans transmission and epidemiological studies $[15,16,34,36]$, and newer genotyping methods of sample DNA have positively corroborated this observation.

Most (94\%) of the suspected human cases we obtained for this study were positive for IS2404. We observed that the proportion of BU-confirmed cases in this study was significantly lower in children ( $<18$ years) than adults ( $\geq 18$ years), suggesting a difference in prevalence among the age categories. However, the $95 \% \mathrm{CI}(14 \%$ to $46 \%)$ is comparable to prevalence estimates from WHO [37]. It is possible that other suspected cases might have been missed during our active case search and subsequently not reported to the health centers for treatment. Most children were at school during case searches. We also noted that, in most cases, infected individuals reported to health centers for treatment only when infection progressed to ulceration; only two out of 30 cases were nodules. Almost all communities showed $100 \%$ positivity in human samples, except Zaibo community in Daloa district, with 33\% positivity. Only $21 \%$ of samples showed ER positivity, with the majority in Ahondo. This slightly contrasts findings by Williamson and colleagues who successfully achieved amplification of the gene in a single reaction [15]. The failure to detect ER in other IS2404-positive samples could be attributed to low DNA concentration or lower bacterial abundance; some of the patients were on treatment during the study period. The use of more sensitive methods, including qPCR, if possible, could improve detection and, thus, should be recommended for laboratories in endemic countries $[15,38]$. In relation to the latter, the use of conventional PCR yields longer amplicons, which are useful for sequence analysis.

Our attempt to amplify four VNTR loci for IS2404-positive samples was challenging both for human and environmental samples. PCR protocols used here had been successfully used to genotype both human and environmental MPM strains collected in Ghana [16]. We suspected that our samples might have had low DNA concentrations as explained previously. The repeat variations of 1, 3 and 9 for MIRU 1 and 2 and 4 for Locus 19 suggest the presence of genetic diversity in MPM strains from Côte d'Ivoire. This length polymorphism in MIRU 1 also explained the limited, but shared homology with isolates from Ghana, as well as the overall genetic differentiation between the two countries. In Ghana, only one allele was reported for MIRU 1 and ST1 in contrast to two for both Locus 6 and Locus 19. In this study, three alleles were seen in MIRU 1 and two in Locus 19, for clinical isolates. Additionally, other MIRU 1 allelic sizes were also detected in environmental isolates. This suggests that MIRU 1 and Locus 19 may be more informative for typing isolates in Côte d'Ivoire. However, a larger sample size is needed to estimate the genetic diversity in these MPM populations. An ST1 
monomorphic repeat of two is inconsistent with findings in Ghana where there was a polymorphism for the locus [16].

Interestingly, the allelic profile $(3,1,2,2)$ is similar to $M$. ulcerans $C$ genotype, circulating in West Africa, particularly in Côte d'Ivoire [13,34]. Similar allelic profiles at some loci, e.g., (_, 1, 2, 2), suggest orthology to $X(1,1,2,2)$ and $(1,1,-$,$) suggest orthology to W(1,1,2,1)$ and $A(1,1,1,2)$ profiles carried by some Ghanaian isolates [16,35]. This may suggest similar strain lineages between the two countries. Interestingly, the Y profile $(1,2,2,1)$, which was found in both human and environmental samples in our previous study in Ghana [18], was not found in this study.

Our phylogenetic analysis showed that three major MPM populations might be circulating in Côte d'Ivoire. On one genetic background, there were isolates (Cluster CI 3) that shared sequence homology with both human and environmental M. ulcerans isolates from Ghana; notably, with two distinct Ghanaian strains, one with a single repeat of MIRU 1 sequence and the other with three repeats. The second MPM population (CI 2) consisted of only environmental isolates. These formed a clade with one human isolate, which was previously identified in Ghana as M. ulcerans [16]. The major branch connecting CI 2 and CI 3 suggests that both populations may have expanded from a common ancestor. The third cluster, CI 1, showed limited similarity to the Ghanaian strains, which suggests that they may be unique to Côte d'Ivoire. They were comprised of both human and environmental isolates. However, these findings should be interpreted cautiously since just a few sequences were used in the analysis. Although these observations were limited to diversity in one locus, our findings provide a hypothesis for using whole genome sequences to explore MPM patho-adaptions in both human and environmental reservoirs.

The majority of the samples clustered with M. ulcerans sequences on the tree. Although IS2404 sequencing identified M. pseudoshottsii DNA in the two human samples, separate analysis using the VNTR loci suggested they were more likely to be M. ulcerans. The discrepancies in MIRU 1 and IS2404 identifications could be due to the presence of mixed genotypes. This is not uncommon, particularly in environmental samples [16]. IS2404 is ubiquitous in most MPMs with high sequence similarity; thus, basing species identification, particularly environmental isolates, solely on the latter may lead to false conclusions. Thus, we suggest that IS2404 typing of isolates, excluding clinical diagnosis, should be complemented with a full set of polymorphic markers. The samples with $M$. pseudoshottsii could be (1) a true M. pseudoshottsii infection or (2) an M. ulcerans with similar IS2404 sequence to that of M. pseudoshottsii. These two hypotheses need further investigation with SNP typing and/or whole genome sequencing. The observance of $M$. liflandii in both environmental and human samples was not surprising. Comparative genome analysis and VNTR typing suggested that $M$. liflandii was an ecovar of $M$. ulcerans $[16,39,40]$. The allelic profile $(3,-2,2)$ observed here is similar to those reported for M. liflandii strains Xt128 and 1138 [13,35]. These observations are consistent with the phylogenetic clustering with $M$. ulcerans.

Transmission of MPMs could occur when individuals at risk come into contact with contaminated environments. Several overlaps occur in water bodies, through water-related activities [41]. In our study communities, a large proportion of respondents were engaged in agricultural activities, particularly fishing and farming. Children helped their parents on farms, and many bathed in the water bodies. These suggest frequent contact with water bodies, which are also sources of drinking water for most inhabitants. Although discrimination of MPMs from environmental samples was not as expected, their presence in nearly all water bodies based on IS2404 amplification, suggests that they could be reservoirs and sources of infection. MPMs were detected in nearly all water bodies, except one.

The two main clusters on the phylogenetic tree comprise both human and environmental isolates (Figure 5). This neighbor joining suggests strain relatedness between the human and environmental isolates. For instance, the branch between the environmental sample SWD1_CI and the human sample SS1_CI suggested a monophyletic relationship. Both samples were from the same community (Sokrogbo, Tiassalé district), which suggests that the water bodies there could be sources of infection. 
Environmental contaminants could inhibit PCR reactions; we observed evidence of many human activities in some water bodies, as some were cloudy and had sediments when filtered on the Whatman filters.

Overall, we observed a significantly higher positivity of NTMs than MPMs in the environment. Thus, there may be a broader and persistent distribution of many Mycobacterium spp. in endemic communities. However, MPM presence may be in select foci, which is consistent with the geographic epidemiology of the disease [42]. MPM presence was not significantly higher in Daloa than in Tiassalé. We observed higher 16S and IS2404 positivity in water filtrands. This contrasts with reports of higher positivity in biofilm samples from Ghana $[13,16]$. Standardization of the sampling protocols between this study and previous studies in Ghana suggests that this discrepancy could be due to the water bodies sampled. In this study, $80 \%$ of the water bodies were ponds compared to the equal number of ponds, streams and rivers in the Ghanaian study [16]. However, the association between $16 \mathrm{~S}$ and IS2404 positivity is consistent with previous data suggesting that the presence of Mycobacterium spp. may not necessarily indicate the presence of some MPMs, particularly M. ulcerans [16]. Although the environmental and human strains shared IS2404 sequence similarity, the absence of VNTR profiles on the environmental strains provides little evidence to track infections in this study.

Finally, we recommend the standardization of protocols employed in BU research; particularly, those employed in routine environmental sampling and PCR analysis [13,16,35].

\section{Conclusions}

We successfully demonstrated that most of the water bodies in this study were contaminated with MPMs, notably M. ulcerans, which could infect inhabitants involved in water-related socio-economic activities. The shared length polymorphisms at the VNTR loci in our strains and other studies in both Côte d'Ivoire and Ghana suggest common ancestral lineages. The allelic copy number in MIRU 1 and Locus 19 suggests diversity in MPM strains from Côte d'Ivoire.

Using standardized sampling and genotyping protocols from Ghana allowed the comparison of datasets. The latter could help explain the role of different ecologies and demography in BU. This study also suggests that distribution, but not the type of MPMs in two BU endemic districts may be significantly different.

The tentative detection of other MPMs like M. pseudoshottsii in human infections highlights their characteristic as opportunistic pathogens. Whole genome analysis can provide insights into possible niche adaptations in the human host. These co-infections may have implications for resistance to drugs used in BU treatment, which only focus on M. ulcerans strains, and lead to larger policy implications in treatment strategies.

Supplementary Materials: The following are available online at http:/ www.mdpi.com/2414-6366/2/1/3/s1. Figure S1. Amplification of IS2404 from some clinical samples. M: 100 bp DNA ladder; Ctl+: positive control (M. ulcerans strain); Ctl-: negative control (sterile water); SA10-SA12b, SS3, SS4, SS8, SS9, SA3b-SG4: clinical samples tested. Figure S2. Amplification of enoyl reductase (ER) gene from clinical samples. M: 100 bp DNA ladder; Ctl+: positive control (M. ulcerans strain); Ctl-: negative control (sterile water); SS1-FA4, SA6-SG4, SA9-SA12b: clinical samples tested. Figure S3. Amplification of VNTR loci from clinical samples. A: Locus 6 amplification; B: ST1 amplification. M: 100 bp DNA ladder; Ctl+: positive control (M. Marinum DL strain); Ctl-: negative control (sterile water); SS1-SG4: clinical samples tested. Figure S4. Amplification of IS2404 from positive 16S rRNA environmental samples. M: 100 bp DNA ladder; Ctl+: positive control (M. Marinum strain); Ctl-: negative controls (sterile water); ZLB1-LNS1: environmental samples tested. Figure S5. Amplification of VNTR loci from environmental samples. A: MIRU 1 amplification; B: Locus 6 amplification. M: 100 bp DNA ladder; Ctl+ 1: positive control (M. Marinum DL strain); Ctl+ 2: positive control (M. ulcerans strain); Ctl-: negative control (sterile water); ZGF1-ABS2 (A), ZGB31-ZLF2 (B): environmental samples tested. Table S1. Primers used for identification of MPMs. Table S2. Size of PCR product of VNTR loci and associated repeat number.

Acknowledgments: We thank the study participants and appreciate the help from staff from the health centers and BU community volunteers during our fieldwork. The authors acknowledge support from the consortium Afrique One "Ecosystem and Population Health: Expanding Frontiers in Health". Afrique One is funded by the Wellcome Trust (WT087535MA). We also acknowledge the support of the West African Centre for Cell Biology of Infectious Pathogens at the Department of Biochemistry, Cell and Molecular Biology at the University of Ghana. 
Author Contributions: This work was carried out in collaboration between all authors. C.D., C.A.N, L.M., C.Q., D.O.K. and B.B. conceived of and designed the study. C.D., C.A.N. and L.M. wrote the protocol. C.D. managed the literature searches and performed the experiments. C.D., C.A.N. L.M., C.Q., D.O.K., J.A.D. and B.B. analyzed the data and wrote the paper. C.D., C.A.N, L.M. and B.B. contributed reagents/materials/analysis tools.

Conflicts of Interest: The authors declare no conflict of interest. The founding sponsors had no role in the design of the study; in the collection, analyses or interpretation of data; in the writing of the manuscript; nor in the decision to publish the results.

\section{References}

1. Stienstra, Y.; van der Graaf, W.T.; Asamoa, K.; van der Werf, T.S. Beliefs and attitudes toward Buruli ulcer in Ghana. Am. J. Trop. Med. Hyg. 2002, 67, 207-213. [PubMed]

2. Walsh, D.S.; Portaels, F.; Meyers, W.M. Recent advances in leprosy and Buruli ulcer (Mycobacterium ulcerans infection). Curr. Opin. Infect. Dis. 2010, 23, 445-455. [CrossRef] [PubMed]

3. Rhodes, M.W.; Kator, H.; Kotob, S.; van Berkum, P.; Kaattari, I.; Vogelbein, W.; Floyd, M.M.; Butler, W.R.; Quinn, F.D.; Ottinger, C.; et al. A unique Mycobacterium species isolated from an epizootic of striped bass (Morone saxatilis). Emerg. Infect. Dis. 2001, 7, 896-899. [CrossRef] [PubMed]

4. Mve-Obiang, A.; Lee, R.E.; Umstot, E.S.; Trott, K.A.; Grammer, T.C.; Parker, J.M.; Ranger, B.S.; Grainger, R.; Mahrous, E.A.; Small, P.L. A newly discovered mycobacterial pathogen isolated from laboratory colonies of Xenopus species with lethal infections produces a novel form of mycolactone, the Mycobacterium ulcerans macrolide toxin. Infect. Immun. 2005, 73, 3307-3312. [CrossRef] [PubMed]

5. Johnson, P.D.; Stinear, T.; Small, P.L.; Pluschke, G.; Merritt, R.W.; Portaels, F.; Huygen, K.; Hayman, J.A.; Asiedu, K. Buruli ulcer (M. ulcerans infection): New insights, new hope for disease control. PLoS Med. 2005, 2, e108. [CrossRef] [PubMed]

6. Kanga, J.; Kacou, E.; Kouamé, K.; Kassi, K.; Kaloga, M.; Yao, J.M.; Dion-Lainé, M.; Avoaka, L.; Yoboué-Yao, P.; Sangaré, A.; et al. La lutte contre l'ulcère de Buruli. Expérience de la Côte d'Ivoire. Bull. Soc. Pathol. Exot. 2005, 99, 34-38. [CrossRef]

7. Ahoua, L.; Aka, N.; Ekaza, E.; Bouzid, S.; N'Guessan, R.; Dosso, M. Risk factors for Buruli ulcer in Côte d'Ivoire: Results of a case-control study. Afr. J. Biotechnol. 2009, 8, 536-546.

8. Marston, B.J.; Diallo, M.O.; Horsburgh, C.R., Jr.; Diomande, I.; Saki, M.Z.; Kanga, J.M.; Patrice, G.; Lipman, H.B.; Ostroff, S.M.; Good, R.C. Emergence of Buruli ulcer disease in the Daloa region of Côte d'Ivoire. Am. J. Trop. Med. Hyg. 1995, 52, 219-224. [PubMed]

9. Asiedu, K.; Etuaful, S. Socioeconomic implications of Buruli ulcer in Ghana: A three-year review. Am. J. Trop. Med. Hyg. 1998, 59, 1015-1022. [PubMed]

10. Debacker, M.; Portaels, F.; Aguiar, J.; Steunou, C.; Zinsou, C.; Meyers, W.; Dramaix, M. Risk factors for Buruli ulcer, Benin. Emerg. Infect. Dis. 2006, 12, 1325-1331. [CrossRef] [PubMed]

11. Brou, T.; Broutin, H.; Elguero, E.; Asse, H.; Guegan, J.F. Landscape diversity related to Buruli ulcer disease in Côte d'Ivoire. PLoS Negl. Trop. Dis. 2008, 2, e271. [CrossRef] [PubMed]

12. Portaels, F.; Meyers, W.M.; Ablordey, A.; Castro, A.G.; Chemlal, K.; de Rijk, P.; Elsen, P.; Fissette, K.; Fraga, A.G.; Lee, R.; et al. First cultivation and characterization of Mycobacterium ulcerans from the environment. PLoS Negl. Trop. Dis. 2008, 2, e178. [CrossRef] [PubMed]

13. Williamson, H.R.; Benbow, M.E.; Nguyen, K.D.; Beachboard, D.C.; Kimbirauskas, R.K.; McIntosh, M.D.; Quaye, C.; Ampadu, E.O.; Boakye, D.; Merritt, R.W.; et al. Distribution of Mycobacterium ulcerans in Buruli ulcer endemic and non-endemic aquatic sites in Ghana. PLoS Negl. Trop. Dis. 2008, 2, e205. [CrossRef] [PubMed]

14. Doannio, J.; Konan, K.; Dosso, F.; Kone, A.; Konan, Y.; Sankare, Y.; Ekaza, E.; Coulibaly, N.; Odehouri, K.; Dosso, M.; et al. Micronecta sp (Corixidae) et Diplonychus sp (Belostomatidae), deux hémiptères aquatiques hôtes et/ou vecteurs potentiels de Mycobacterium ulcerans agent pathogène de l'ulcère de Buruli en Côte d'Ivoire. Med. Trop. 2011, 71, 53-57.

15. Williamson, H.R.; Benbow, M.E.; Campbell, L.P.; Johnson, C.R.; Sopoh, G.; Barogui, Y.; Merritt, R.W.; Small, P.L.C. Detection of Mycobacterium ulcerans in the Environment Predicts Prevalence of Buruli Ulcer in Benin. PLoS Negl. Trop. Dis. 2012, 6, e1506. [CrossRef] [PubMed] 
16. Narh, C.A.; Mosi, L.; Quaye, C.; Dassi, C.; Konan, D.O.; Tay, S.C.K.; de Souza, D.K.; Boakye, D.A.; Bonfoh, B. Source Tracking Mycobacterium ulcerans Infections in the Ashanti Region, Ghana. PLoS Negl. Trop. Dis. 2015, 9, e0003437. [CrossRef] [PubMed]

17. Yeboah-Manu, D.; Röltgen, K.; Opare, W.; Asan-Ampah, K.; Quenin-Fosu, K.; Asante-Poku, A.; Ampadu, E.; Fyfe, J.; Koram, K.; Ahorlu, C.; et al. Sero-Epidemiology as a Tool to Screen Populations for Exposure to Mycobacterium ulcerans. PLoS Negl. Trop. Dis. 2012, 6, e1460. [CrossRef] [PubMed]

18. Ablordey, A.; Swings, J.; Hubans, C.; Chemlal, K.; Locht, C.; Portaels, F.; Supply, P. Multilocus variable-number tandem repeat typing of Mycobacterium ulcerans. J. Clin. Microbiol. 2005, 43, 1546-1551. [CrossRef] [PubMed]

19. Hilty, M.; Yeboah-Manu, D.; Boakye, D.; Mensah-Quainoo, E.; Rondini, S.; Schelling, E.; Ofori-Adjei, D.; Portaels, F.; Zinsstag, J.; Pluschke, G. Genetic diversity in Mycobacterium ulcerans isolates from Ghana revealed by a newly identified locus containing a variable number of tandem repeats. J. Bacteriol. 2006, 188, 1462-1465. [CrossRef] [PubMed]

20. Stragier, P.; Ablordey, A.; Bayonne, L.; Lugor, Y.; Sindani, I.; Suykerbuyk, P.; Wabinga, H.; Meyers, W.; Portaels, F. Heterogeneity among Mycobacterium ulcerans Isolates from Africa. Emerg. Infect. Dis. 2006, 12, 844-847. [CrossRef] [PubMed]

21. Ablordey, A.; Fonteyne, P.-A.; Stragier, P.; Vandamme, P.; Portaels, F. Identification of a new variable number tandem repeat locus in Mycobacterium ulcerans for potential strain discrimination among African isolates. Clin. Microbiol. Infect. 2007, 13, 734-736. [CrossRef] [PubMed]

22. Yip, M.J.; Porter, J.L.; Fyfe, J.A.M.; Lavender, C.J.; Portaels, F.; Rhodes, M.; Kator, H.; Colorni, A.; Jenkin, G.A.; Stinear, T. Evolution of Mycobacterium ulcerans and Other Mycolactone-Producing Mycobacteria from a Common Mycobacterium marinum Progenitor. J. Bacteriol. 2007, 189, 2021-2029. [CrossRef] [PubMed]

23. Kaser, M.; Gutmann, O.; Hauser, J.; Stinear, T.; Cole, S.; Yeboah-Manu, D.; Dernick, G.; Certa, U.; Pluschke, G. Lack of insertional-deletional polymorphism in a collection of Mycobacterium ulcerans isolates from Ghanaian Buruli ulcer patients. J. Clin. Microbiol. 2009, 47, 3640-3646. [CrossRef] [PubMed]

24. Roltgen, K.; Qi, W.; Ruf, M.T.; Mensah-Quainoo, E.; Pidot, S.J.; Seemann, T.; Stinear, T.P.; Kaser, M.; Yeboah-Manu, D.; Pluschke, G. Single nucleotide polymorphism typing of Mycobacterium ulcerans reveals focal transmission of buruli ulcer in a highly endemic region of Ghana. PLoS Negl. Trop. Dis. 2010, 4, e751. [CrossRef] [PubMed]

25. Dassi, C.; Mosi, L.; Akpatou, B.; Narh, A.C.; Quaye, C.; Konan, O.D.; Djaman, A.J.; Bonfoh, B. Detection of Mycobacterium ulcerans in Mastomys natalensis and Potential Transmission in Buruli ulcer Endemic Areas in Côte d'Ivoire. Mycobact. Dis. 2015, 5. [CrossRef]

26. Portaels, F.; WHO. Laboratory diagnosis of Buruli ulcer: A manual for health care providers. Available online: http:/ /www.who.int/iris/handle/10665/111738 (accessed on 29 December 2016).

27. Ablordey, A.; Hilty, M.; Stragier, P.; Swings, J.; Portaels, F. Comparative nucleotide sequence analysis of polymorphic variable-number tandem-repeat loci in Mycobacterium ulcerans. J. Clin. Microbiol. 2005, 43, 5281-5284. [CrossRef] [PubMed]

28. Stragier, P.; Ablordey, A.; Meyers, W.M.; Portaels, F. Genotyping Mycobacterium ulcerans and Mycobacterium marinum by using mycobacterial interspersed repetitive units. J. Bacteriol. 2005, 187, 1639-1647. [CrossRef] [PubMed]

29. Hilty, M.; Kaser, M.; Zinsstag, J.; Stinear, T.; Pluschke, G. Analysis of the Mycobacterium ulcerans genome sequence reveals new loci for variable number tandem repeats (VNTR) typing. Microbiology 2007, 153, 1483-1487. [CrossRef] [PubMed]

30. Lavender, C.J.; Stinear, T.P.; Johnson, P.D.; Azuolas, J.; Benbow, M.E.; Wallace, J.R.; Fyfe, J.A. Evaluation of VNTR typing for the identification of Mycobacterium ulcerans in environmental samples from Victoria, Australia. FEMS Microbiol. Lett. 2008, 287, 250-255. [CrossRef] [PubMed]

31. Altschul, S.F.; Gish, W.; Miller, W.; Myers, E.W.; Lipman, D.J. Basic local alignment search tool. J. Mol. Biol. 1990, 215, 403-410. [CrossRef]

32. Katoh, K.; Misawa, K.; Kuma, K.-I.; Miyata, T. MAFFT: A novel method for rapid multiple sequence alignment based on fast Fourier transform. Nucleic Acids Res. 2002, 30, 3059-3066. [CrossRef] [PubMed]

33. Price, M.N.; Dehal, P.S.; Arkin, A.P. FastTree 2-Approximately Maximum-Likelihood Trees for Large Alignments. PLoS ONE 2010, 5, e9490. [CrossRef] [PubMed] 
34. Ngazoa-Kakou, E.S.; Coulibaly-N'Golo, D.; Aka, N.; Vakou, S.; Aoussi, S.; Dosso, M. Clonality of Mycobacterium ulcerans by Using VNTR-MIRU Typing in Ivory Coast (Côte d'Ivoire), West Africa. Int. J. Trop. Dis. Health 2015, 7, 163-171.

35. Williamson, H.; Phillips, R.; Sarfo, S.; Wansbrough-Jones, M.; Small, P. Genetic Diversity of PCR-Positive, Culture-Negative and Culture-Positive Mycobacterium ulcerans Isolated from Buruli Ulcer Patients in Ghana. PLOS ONE 2014, 9, e88007. [CrossRef] [PubMed]

36. Narh, C.; Mosi, L.; Quaye, C.; Tay, S.; Bonfoh, B.; de Souza, D. Genotyping Tools for Mycobacterium ulcerans Drawbacks and Future Prospects. Mycobact. Dis. 2014, 4, 1000149. [CrossRef] [PubMed]

37. WHO. Number of new cases of Buruli ulcer reported. Available online: http:/ /apps.who.int (accessed on 11 March 2015).

38. Vandelannoote, K.; Durnez, L.; Amissah, D.; Gryseels, S.; Dodoo, A.; Yeboah, S.; Addo, P.; Eddyani, M.; Leirs, H.; Ablordey, A.; et al. Application of real-time PCR in Ghana, a Buruli ulcer-endemic country, confirms the presence of Mycobacterium ulcerans in the environment. FEMS Microbiol. Lett. 2010, 304, 191-194. [CrossRef] [PubMed]

39. Godfrey, D.; Williamson, H.; Silverman, J.; Small, P.L. Newly identified Mycobacterium species in a Xenopus laevis colony. Comp. Med. 2007, 57, 97-104. [PubMed]

40. Tobias, N.J.; Doig, K.D.; Medema, M.H.; Chen, H.; Haring, V.; Moore, R.; Seemann, T.; Stinear, T.P. Complete genome sequence of the frog pathogen Mycobacterium ulcerans ecovar Liflandii. J. Bacteriol. 2013, 195, 556-564. [CrossRef] [PubMed] 
41. Primm, T.P.; Lucero, C.A.; Falkinham, J.O. Health impacts of environmental mycobacteria. Clin. Microbiol. Rev. 2004, 17, 98-106. [CrossRef] [PubMed]

42. Wagner, T.; Benbow, M.E.; Brenden, T.O.; Qi, J.; Johnson, R.C. Buruli ulcer disease prevalence in Benin, West Africa: Associations with land use/cover and the identification of disease clusters. Int. J. Health Geogr. 2008, 7, 25. [CrossRef] [PubMed]

(c)

(C) 2017 by the authors. Licensee MDPI, Basel, Switzerland. This article is an open access article distributed under the terms and conditions of the Creative Commons Attribution (CC BY) license (http:/ / creativecommons.org/licenses/by/4.0/). 